\title{
Existence of nontrivial weak homoclinic orbits for second-order impulsive differential equations
}

Hui Fang ${ }^{*}$ and Hongbo Duan

\section{"Correspondence:}

kmustfanghui@hotmail.com

Department of Mathematics, Kunming University of Science and

Technology, Kunming, Yunnan 650500, China

\begin{abstract}
A sufficient condition is obtained for the existence of nontrivial weak homoclinic orbits of second-order impulsive differential equations by employing the mountain pass theorem, a weak convergence argument and a weak version of Lieb's lemma.
\end{abstract}

\section{Introduction}

Fečkan [1], Battelli and Fečkan [2] studied the existence of homoclinic solutions for impulsive differential equations by using perturbation methods. Tang et al. [3-6] studied the existence of homoclinic solutions for Hamiltonian systems via variational methods. In recent years, many researchers have paid much attention to multiplicity and existence of solutions of impulsive differential equations via variational methods (for example, see [7-12]). However, few papers have been published on the existence of homoclinic solutions for second-order impulsive differential equations via variational methods.

In this paper, we consider the following impulsive differential equations:

$$
\begin{aligned}
& q^{\prime \prime}(t)+V^{\prime}(t, q(t))=0, \quad \text { a.e. } t \in\left(t_{j}, t_{j+1}\right), j \in \mathbb{Z}, \\
& q^{\prime}\left(t_{j}^{+}\right)-q^{\prime}\left(t_{j}^{-}\right)=I\left(q\left(t_{j}\right)\right), \quad j \in \mathbb{Z},
\end{aligned}
$$

where $V: \mathbb{R} \times \mathbb{R} \rightarrow \mathbb{R}$ is of class $C^{1}, V(t, 0)=V^{\prime}(t, 0)=0$ with $V^{\prime}(t, x)=(\partial V / \partial x)(t, x)$, and $I \in C(\mathbb{R}, \mathbb{R})$ with $I(0)=0$. $\mathbb{Z}$ denotes the set of all integers, and $t_{j}(j \in \mathbb{Z})$ are impulsive points. Moreover, there exist a positive integer $p$ and a positive constant $T$ such that $0<$ $t_{0}<t_{1}<\cdots<t_{p-1}<T, t_{l+k p}=t_{l}+k T, \forall k \in \mathbb{Z}, l=0,1, \ldots, p-1 . q^{\prime}\left(t_{j}^{+}\right)=\lim _{h \rightarrow 0^{+}} q^{\prime}\left(t_{j}+h\right)$ and $q^{\prime}\left(t_{j}^{-}\right)=\lim _{h \rightarrow 0^{+}} q^{\prime}\left(t_{j}-h\right)$ represent the right and left limits of $q^{\prime}(t)$ at $t=t_{j}$ respectively.

We say that a function $q(t)$ is a weak homoclinic orbit of Eqs. (1.1) and (1.2) if $q$ satisfies (1.1) and

$$
q \in\left\{q \in C(\mathbb{R}, \mathbb{R}): \sum_{j=-\infty}^{+\infty}\left|q\left(t_{j}\right)\right|^{2}<+\infty, q^{\prime} \in L^{2}(\mathbb{R}), q( \pm \infty)=0, q(k T)=0, k \in \mathbb{Z}\right\}
$$

Motivated by the works of Nieto and Regan [7], Smets and Willem [13], in this paper we study the existence of nontrivial weak homoclinic orbits of (1.1)-(1.2) by using the mountain pass theorem, a weak version of Lieb's lemma and a weak convergence argument. Our method is different from those of $[8,9]$.

(C) 2012 Fang and Duan; licensee Springer. This is an Open Access article distributed under the terms of the Creative Commons Attribution License (http://creativecommons.org/licenses/by/2.0), which permits unrestricted use, distribution, and reproduction in any medium, provided the original work is properly cited. 
The main result is the following.

Theorem 1.1 Assume that Eqs. (1.1) and (1.2) satisfy the following conditions:

$\left(\mathrm{H}_{1}\right)$ There exists a positive number $T$ such that

$$
V^{\prime}(t+T, x)=V^{\prime}(t, x), \quad V(t+T, x)=V(t, x), \quad \forall(t, x) \in \mathbb{R}^{2}
$$

$\left(\mathrm{H}_{2}\right) \lim _{x \rightarrow 0} \frac{V^{\prime}(t, x)}{x}=0$ uniformly for $t \in \mathbb{R}$;

$\left(\mathrm{H}_{3}\right)$ There exists a constant $\mu>2$ such that

$$
x V^{\prime}(t, x) \geq \mu V(t, x)>0, \quad \forall(t, x) \in \mathbb{R} \times \mathbb{R} \backslash\{0\}
$$

$\left(\mathrm{H}_{4}\right)$ There exist constants $a_{0}>0$ and $a_{1}>0$ such that

$$
\begin{aligned}
& V(t, x) \geq a_{0}|x|^{\mu}, \quad \text { for any }|x| \geq 1, t \in \mathbb{R} \\
& V(t, x) \leq a_{1}|x|^{\mu}, \quad \text { for any }|x| \leq 1, t \in \mathbb{R}
\end{aligned}
$$

$\left(\mathrm{H}_{5}\right)$ There exists a constant $b$, with $0<b<\frac{\mu-2}{(\mu+2) T p}$, such that

$$
|I(x)| \leq b|x|
$$

and

$$
2 \int_{0}^{x} I(t) d t-I(x) x \leq 0
$$

Then there exists a nontrivial weak homoclinic orbit of Eqs. (1.1) and (1.2).

Remark 1.1 $\left(\mathrm{H}_{2}\right)$ implies that $q(t) \equiv 0$ is an equilibrium of (1.1)-(1.2).

Remark 1.2 Set $V(t, x)=(2+\sin t) x^{4}, I(x)=\frac{x}{10 \pi p}$. It is easy to see that $V(t, x), I(x)$ satisfy $\left(\mathrm{H}_{1}\right)-\left(\mathrm{H}_{5}\right)$.

\section{Proof of main results}

Lemma 2.1 (Mountain pass lemma [14]) Let E be a Banach space and $\varphi \in C^{1}(E, \mathbb{R}), e \in E$, $r>0$ be such that $\|e\|>r$ and

$$
b:=\inf _{\|y\|=r} \varphi(y)>\varphi(0) \geq \varphi(e) .
$$

Let

$$
\begin{aligned}
& \Gamma=\{\gamma \in C([0,1], E): \gamma(0)=0, \gamma(1)=e\}, \\
& d:=\inf _{\gamma \in \Gamma} \sup _{t \in[0,1]} \varphi(\gamma(t)) .
\end{aligned}
$$

Then, for each $\varepsilon>0, \delta>0$, there exists $y \in E$ such that 
$\left(V_{1}\right) d-2 \varepsilon \leq \varphi(y) \leq d+2 \varepsilon$

$\left(V_{2}\right) \operatorname{dist}(y, E) \leq 2 \delta$

$\left(V_{3}\right)\left\|\varphi^{\prime}(y)\right\| \leq \frac{8 \varepsilon}{\delta}$.

In what follows, $l^{2}$ denotes the space of sequences whose second powers are summable on $\mathbb{Z}$ (the set of all integers), that is,

$$
\sum_{j \in \mathbb{Z}}\left|a_{j}\right|^{2}<+\infty, \quad \forall a=\left\{a_{j}\right\}_{j=-\infty}^{+\infty} \in l^{2} .
$$

The space $l^{2}$ is equipped with the following norm:

$$
\|a\|_{l_{2}}=\left(\sum_{j \in \mathbb{Z}}\left|a_{j}\right|^{2}\right)^{\frac{1}{2}} .
$$

We now prove some technical lemmas.

\section{Lemma 2.2 The space}

$$
H:=\left\{q \in C(\mathbb{R}, \mathbb{R}):\left\{q\left(t_{j}\right)\right\}_{j=-\infty}^{+\infty} \in l^{2}, q^{\prime} \in L^{2}(\mathbb{R}), q( \pm \infty)=0, q(k T)=0, k \in \mathbb{Z}\right\}
$$

is a Hilbert space with the inner product

$$
\left(q_{1}, q_{2}\right)_{H}=\int_{\mathbb{R}} q_{1}^{\prime}(t) q_{2}^{\prime}(t) d t
$$

and the corresponding norm

$$
\|q\|_{H}=\left(\int_{\mathbb{R}}\left|q^{\prime}(t)\right|^{2} d t\right)^{\frac{1}{2}}
$$

Proof Let $\left\{q_{n}\right\}$ be a Cauchy sequence in $H$, then $\left\{q_{n}^{\prime}\right\}$ is a Cauchy sequence in $L^{2}(\mathbb{R})$ and there exists $y \in L^{2}(\mathbb{R})$ such that $\left\{q_{n}^{\prime}\right\}$ converges to $y$ in $L^{2}(\mathbb{R})$. Define the function $q(t)$ as follows:

$$
q(t)=\int_{k T}^{t} y(s) d s, \quad k T \leq t<(k+1) T, k \in \mathbb{Z} .
$$

It is easy to see that

$$
\lim _{h \rightarrow 0^{+}} q(k T-h)=\int_{(k-1) T}^{k T} y(s) d s .
$$

Since $q_{n}(k T)=0, k \in \mathbb{Z}$, we have

$$
\begin{aligned}
\left|\int_{(k-1) T}^{k T} y(s) d s\right| & =\left|\int_{(k-1) T}^{k T} y(s) d s-\left[q_{n}(k T)-q_{n}((k-1) T)\right]\right| \\
& =\left|\int_{(k-1) T}^{k T}\left[y(s)-q_{n}^{\prime}(s)\right] d s\right|
\end{aligned}
$$


Fang and Dian Boundary Value Problems 2012, 2012:138

Page 4 of 13

http://www.boundaryvalueproblems.com/content/2012/1/138

$$
\begin{aligned}
& \leq \int_{(k-1) T}^{k T}\left|y(s)-q_{n}^{\prime}(s)\right| d s \\
& \leq T^{\frac{1}{2}}\left[\int_{(k-1) T}^{k T}\left|y(s)-q_{n}^{\prime}(s)\right|^{2} d s\right]^{\frac{1}{2}} \\
& \leq T^{\frac{1}{2}}\left[\int_{\mathbb{R}}\left|y(s)-q_{n}^{\prime}(s)\right|^{2} d s\right]^{\frac{1}{2}},
\end{aligned}
$$

which implies that $\int_{(k-1) T}^{k T} y(s) d s=0$, that is, $q\left(k T^{-}\right)=0, k \in \mathbb{Z}$. Therefore, $q$ is continuous. Thus, $q \in C(\mathbb{R}, \mathbb{R})$ and $q^{\prime}=y$.

Noticing that, for $k T \leq t<(k+1) T$, we have

$$
\begin{aligned}
|q(t)|^{2} & =\left|\int_{k T}^{t} y(s) d s\right|^{2} \leq\left[\int_{k T}^{(k+1) T}|y(s)| d s\right]^{2} \\
& \leq T \int_{k T}^{(k+1) T}|y(s)|^{2} d s=T \int_{k T}^{+\infty}|y(s)|^{2} d s-T \int_{(k+1) T}^{+\infty}|y(s)|^{2} d s,
\end{aligned}
$$

which implies $q( \pm \infty)=0$. On the other hand, since

$$
\sum_{j=-\infty}^{+\infty}\left|q\left(t_{j}\right)\right|^{2}=\sum_{l=0}^{p-1} \sum_{k=-\infty}^{+\infty}\left|q\left(t_{l+k p}\right)\right|^{2}
$$

and $k T<t_{l+k p}=t_{l}+k T<(k+1) T(l=0,1, \ldots, p-1)$, we have

$$
\left|q\left(t_{l+k p}\right)\right|^{2}=\left|\int_{k T}^{t_{l+k p}} y(s) d s\right|^{2} \leq T \int_{k T}^{(k+1) T}|y(s)|^{2} d s .
$$

Therefore,

$$
\sum_{j=-\infty}^{+\infty}\left|q\left(t_{j}\right)\right|^{2} \leq \sum_{l=0}^{p-1} \sum_{k=-\infty}^{+\infty} T \int_{k T}^{(k+1) T}|y(s)|^{2} d s=p T \int_{\mathbb{R}}|y(s)|^{2} d s<+\infty
$$

Consequently, $q \in H$ and $\left\{q_{n}\right\}$ converges to $q$ in $H$. The proof is complete.

Lemma 2.3 For any $q \in H$, the following inequalities hold:

$$
|q|_{\infty}:=\sup _{t \in \mathbb{R}}|q(t)| \leq T^{\frac{1}{2}}\|q\|_{H}, \quad|q|_{2}:=\left[\int_{\mathbb{R}}|q(t)|^{2} d t\right]^{\frac{1}{2}} \leq T\|q\|_{H} .
$$

Furthermore, $q \in H^{1}(\mathbb{R})$ and

$$
\begin{aligned}
& \|q\|_{H^{1}}:=\left[\int_{\mathbb{R}}\left(|q(t)|^{2}+\left|q^{\prime}(t)\right|^{2}\right) d t\right]^{\frac{1}{2}} \leq\left[T^{2}+1\right]^{\frac{1}{2}}\|q\|_{H}, \\
& \sum_{j=-\infty}^{+\infty}\left|q\left(t_{j}\right)\right|^{2} \leq T p\|q\|_{H^{2}}^{2}
\end{aligned}
$$


Proof For any $t \in \mathbb{R}$, there exists an integer $k$ such that $(k-1) T \leq t<k T$. Then it follows from Cauchy-Schwarz inequality that

$$
\begin{aligned}
|q(t)| & =|q(k T)-q(t)| \leq \int_{t}^{k T}\left|q^{\prime}(s)\right| d s \leq \int_{(k-1) T}^{k T}\left|q^{\prime}(s)\right| d s \\
& \leq T^{\frac{1}{2}}\left(\int_{(k-1) T}^{k T}\left|q^{\prime}(s)\right|^{2} d s\right)^{\frac{1}{2}} \leq T^{\frac{1}{2}}\|q\|_{H},
\end{aligned}
$$

which implies $|q|_{\infty} \leq T^{\frac{1}{2}}\|q\|_{H}$.

Furthermore, from the above argument, we have

$$
\sum_{k=-\infty}^{+\infty} \int_{(k-1) T}^{k T}|q(t)|^{2} d t \leq T^{2} \sum_{k=-\infty}^{+\infty} \int_{(k-1) T}^{k T}\left|q^{\prime}(t)\right|^{2} d t=T^{2}\|q\|_{H}^{2},
$$

that is, $|q|_{2} \leq T\|q\|_{H}$.

Since

$$
\begin{aligned}
& \left|q^{\prime}\right|_{2}=\left(\int_{\mathbb{R}}\left|q^{\prime}(t)\right|^{2} d t\right)^{\frac{1}{2}}=\|q\|_{H}, \\
& \|q\|_{H^{1}}=\left[\int_{\mathbb{R}}\left(|q(t)|^{2}+\left|q^{\prime}(t)\right|^{2}\right) d t\right]^{\frac{1}{2}} \leq\left[T^{2}+1\right]^{\frac{1}{2}}\|q\|_{H} .
\end{aligned}
$$

Finally, we obtain that

$$
\begin{aligned}
\sum_{j=-\infty}^{+\infty}\left|q\left(t_{j}\right)\right|^{2} & =\sum_{l=0}^{p-1} \sum_{k=-\infty}^{+\infty}\left|q\left(t_{l}+k T\right)\right|^{2}=\sum_{l=0}^{p-1} \sum_{k=-\infty}^{+\infty}\left|\int_{t_{l}+k T}^{(k+1) T} q^{\prime}(s) d s\right|^{2} \\
& \leq \sum_{l=0}^{p-1} \sum_{k=-\infty}^{+\infty}\left[\int_{k T}^{(k+1) T}\left|q^{\prime}(s)\right| d s\right]^{2} \\
& \leq p T \sum_{k=-\infty}^{+\infty} \int_{k T}^{(k+1) T}\left|q^{\prime}(s)\right|^{2} d s \\
& =p T\|q\|_{H}^{2} .
\end{aligned}
$$

The proof is complete.

Define the functional $\varphi: H \rightarrow \mathbb{R}$ as follows:

$$
\varphi(q)=\frac{1}{2} \int_{\mathbb{R}}\left|q^{\prime}(t)\right|^{2} d t-\int_{\mathbb{R}} V(t, q(t)) d t+\sum_{j=-\infty}^{+\infty} \int_{0}^{q\left(t_{j}\right)} I(s) d s, \quad q \in H .
$$

Lemma 2.4 If $\left(\mathrm{H}_{1}\right)-\left(\mathrm{H}_{5}\right)$ hold, then $\varphi \in C^{1}(H, \mathbb{R})$ and

$$
\left\langle\varphi^{\prime}(q), h\right\rangle=\int_{\mathbb{R}} q^{\prime}(t) h^{\prime}(t) d t-\int_{\mathbb{R}} V^{\prime}(t, q(t)) h(t) d t+\sum_{j=-\infty}^{+\infty} I\left(q\left(t_{j}\right)\right) h\left(t_{j}\right), \quad \forall h \in H .
$$


Proof From the continuity of $V, V^{\prime}$ and $\left(\mathrm{H}_{2}\right)-\left(\mathrm{H}_{3}\right)$, we see that, for each $\gamma>0$, there exists $C_{\gamma}>0$, such that

$$
\left|V^{\prime}(t, x)\right| \leq C_{\gamma}|x|, \quad|V(t, x)| \leq \frac{1}{2} C_{\gamma}|x|^{2}, \quad \forall t \in \mathbb{R},|x| \leq \gamma .
$$

Since $q(t) \rightarrow 0$ as $t \rightarrow \infty$, there exists $\rho_{\gamma}>0$ such that

$$
|q(t)| \leq \gamma, \quad \text { whenever }|t| \geq \rho_{\gamma} .
$$

Therefore, we have

$$
\left|V^{\prime}(t, q(t))\right| \leq C_{\gamma}|q(t)|, \quad|V(t, q(t))| \leq \frac{1}{2} C_{\gamma}|q(t)|^{2}, \quad \text { for all }|t| \geq \rho_{\gamma} .
$$

It follows from $\left(\mathrm{H}_{5}\right)$ that, $\forall q, h \in H$,

$$
\begin{aligned}
\left|\sum_{j=-\infty}^{+\infty} I\left(q\left(t_{j}\right)\right) h\left(t_{j}\right)\right| & \leq \sum_{j=-\infty}^{+\infty}\left|I\left(q\left(t_{j}\right)\right)\right|\left|h\left(t_{j}\right)\right| \leq \sum_{j=-\infty}^{+\infty} b\left|q\left(t_{j}\right)\right|\left|h\left(t_{j}\right)\right| \\
& \leq b\left(\sum_{j=-\infty}^{+\infty}\left|q\left(t_{j}\right)\right|^{2}\right)^{\frac{1}{2}}\left(\sum_{j=-\infty}^{+\infty}\left|h\left(t_{j}\right)\right|^{2}\right)^{\frac{1}{2}}<+\infty,
\end{aligned}
$$

and

$$
\sum_{j=-\infty}^{+\infty}\left|\int_{0}^{q\left(t_{j}\right)} I(s) d s\right| \leq \sum_{j=-\infty}^{+\infty} \int_{\min \left\{0, q\left(t_{j}\right)\right\}}^{\max \left\{0, q\left(t_{j}\right)\right\}}|I(s)| d s \leq \frac{b}{2} \sum_{j=-\infty}^{+\infty}\left|q\left(t_{j}\right)\right|^{2}<+\infty .
$$

Thus, $\varphi$ and the right hand of (2.5) is well defined on $H$. By the definition of Fréchet derivative, it is easy to see that $\varphi \in C^{1}(H, \mathbb{R})$ and (2.5) holds.

Lemma 2.5 If $q \in H$ is a critical point of the functional $\varphi$, then $q$ satisfies (1.1).

Proof If $q \in H$ is a critical point of the functional $\varphi$, then for any $h \in C_{0}^{\infty}(\mathbb{R})$, we have

$$
0=\left\langle\varphi^{\prime}(q), h\right\rangle=\int_{\mathbb{R}} q^{\prime}(t) h^{\prime}(t) d t-\int_{R} V^{\prime}(t, q(t)) h(t) d t+\sum_{j=-\infty}^{+\infty} I\left(q\left(t_{j}\right)\right) h\left(t_{j}\right) .
$$

$\forall j \in \mathbb{Z}$, take $h \in C_{0}^{\infty}(\mathbb{R})$ such that $h(t)=0$ for any $t \in\left(-\infty, t_{j}\right] \cup\left[t_{j+1},+\infty\right)$, and $h \in$ $C_{0}^{\infty}\left(\left[t_{j}, t_{j+1}\right]\right)$. Therefore, we have

$$
0=\int_{t_{j}}^{t_{j+1}} q^{\prime}(t) h^{\prime}(t) d t-\int_{t_{j}}^{t_{j+1}} V^{\prime}(t, q(t)) h(t) d t
$$

by the definition of the weak derivative, which implies

$$
q^{\prime \prime}(t)+V^{\prime}(t, q(t))=0 \quad \text { a.e. on }\left(t_{j}, t_{j+1}\right)
$$

Hence, the critical point $q \in H$ of the functional $\varphi$ satisfies (1.1). The proof is complete. 
Lemma 2.6 Under the assumptions $\left(\mathrm{H}_{1}\right)-\left(\mathrm{H}_{5}\right)$, there exists $e \in H$ and $r>0$ such that $\|e\|_{H}>r$ and

$$
b:=\inf _{\|y\|_{H}=r} \varphi(y)>\varphi(0) \geq \varphi(e) .
$$

Proof If $q \in H$ and $\|q\|_{H} \leq \frac{1}{T^{\frac{1}{2}}}$, then, by Lemma 2.3, $|q|_{\infty} \leq 1$. Hence, by $\left(\mathrm{H}_{5}\right)$ and Lemma 2.3, we have

$$
\begin{aligned}
\sum_{j=-\infty}^{+\infty} \int_{0}^{q\left(t_{j}\right)} I(s) d s & \geq-\sum_{j=-\infty}^{+\infty} \int_{\min \left\{0, q\left(t_{j}\right)\right\}}^{\max \left\{0, q\left(t_{j}\right)\right\}}|I(s)| d s \\
& \geq-\frac{1}{2} \sum_{j=-\infty}^{+\infty} b\left|q\left(t_{j}\right)\right|^{2} \geq-\frac{1}{2} b T p\|q\|_{H}^{2},
\end{aligned}
$$

and

$$
\sum_{j=-\infty}^{+\infty} I\left(q\left(t_{j}\right)\right) q\left(t_{j}\right) \leq \sum_{j=-\infty}^{+\infty}\left|I\left(q\left(t_{j}\right)\right)\right|\left|q\left(t_{j}\right)\right| \leq \sum_{j=-\infty}^{+\infty} b\left|q\left(t_{j}\right)\right|^{2} \leq b T p\|q\|_{H}^{2} .
$$

It follows from (2.8), $\left(\mathrm{H}_{4}\right)$ and Lemma 2.3 that

$$
\begin{aligned}
\varphi(q) & =\frac{1}{2}\|q\|_{H}^{2}-\int_{\mathbb{R}} V(t, q(t)) d t+\sum_{j=-\infty}^{+\infty} \int_{0}^{q\left(t_{j}\right)} I(s) d s \\
& \geq \frac{1}{2}\|q\|_{H}^{2}-a_{1} \int_{\mathbb{R}}|q(t)|^{\mu} d t-\frac{1}{2} b T p\|q\|_{H}^{2} \\
& \geq \frac{1}{2}\|q\|_{H}^{2}-a_{1}|q|_{\infty}^{\mu-2} \int_{\mathbb{R}}|q(t)|^{2} d t-\frac{1}{2} b T p\left\|^{2}\right\|_{H}^{2} \\
& \geq \frac{1}{2}(1-b T p)\|q\|_{H}^{2}-a_{1} T^{\frac{\mu+2}{2}}\|q\|_{H}^{\mu} .
\end{aligned}
$$

Therefore, as $\mu>2$ and $b<\frac{\mu-2}{(\mu+2) T p}<\frac{1}{T p}$, there exists $r>0$ such that $\inf _{\|q\|_{H}=r} \varphi(q)>0$.

Now, let $v \in H \backslash\{0\}$ and $\lambda>1$. Then there exists a subset $(a, b)$ of $\mathbb{R}$ and $\lambda$ large enough such that

$$
\lambda|v(t)|>1, \quad \text { for all } t \in(a, b) .
$$

Since $V(t, \lambda v(t)) \geq 0$, by (2.4), $\left(\mathrm{H}_{4}\right)$ and Lemma 2.3, we have

$$
\begin{aligned}
\varphi(\lambda v) & \leq \frac{\lambda^{2}}{2} \int_{\mathbb{R}}\left|v^{\prime}(t)\right|^{2} d t-\int_{a}^{b} V(t, \lambda v(t)) d t+\sum_{j=-\infty}^{+\infty} \int_{0}^{\lambda v\left(t_{j}\right)} I(s) d s \\
& \leq \frac{\lambda^{2}}{2}\|v\|_{H}^{2}-a_{0} \lambda^{\mu} \int_{a}^{b}|v(t)|^{\mu} d t+\frac{\lambda^{2}}{2} b T p\|v\|_{H}^{2} \\
& =\frac{\lambda^{2}}{2}(1+b T p)\|v\|_{H}^{2}-a_{0} \lambda^{\mu} \int_{a}^{b}|v(t)|^{\mu} d t .
\end{aligned}
$$

Since $\mu>2$, the right-hand member is negative of $\lambda$ sufficiently large, and there exists $e:=\lambda v \in H$ such that $\|e\|_{H}>r, \varphi(e) \leq 0$. The proof is complete. 
Lemma 2.7 Under the assumptions $\left(\mathrm{H}_{1}\right)-\left(\mathrm{H}_{5}\right)$, there exists a bounded sequence $\left\{q_{n}\right\}$ in $H$ such that

$$
\varphi\left(q_{n}\right) \rightarrow d, \quad \varphi^{\prime}\left(q_{n}\right) \rightarrow 0, \quad \operatorname{dist}\left(q_{n}, H\right) \rightarrow 0,
$$

where $d:=\inf _{\gamma \in \Gamma} \sup _{t \in[0,1]} \varphi(\gamma(t)), \Gamma=\{\gamma \in C([0,1], H): \gamma(0)=0, \gamma(1)=e\}$. Furthermore, $q_{n}$ does not converge to 0 in measure.

Proof All we have to prove is that any sequence $\left\{q_{n}\right\}$ obtained by taking $\varepsilon=1 / n^{2}$ and $\delta=1 / n$ in Lemma 2.1 is bounded and $q_{n}$ does not converge to 0 in measure. For $n$ sufficiently large, it follows from $\left(\mathrm{H}_{3}\right),\left(\mathrm{H}_{5}\right),(2.4),(2.5),(2.8)$ and (2.9) that

$$
\begin{aligned}
d+1+\left\|q_{n}\right\|_{H} \geq & \varphi\left(q_{n}\right)-\frac{1}{\mu}\left\langle\varphi^{\prime}\left(q_{n}\right), q_{n}\right\rangle \\
= & \left(\frac{1}{2}-\frac{1}{\mu}\right) \int_{\mathbb{R}}\left|q_{n}^{\prime}(t)\right|^{2} d t-\int_{\mathbb{R}}\left[V\left(t, q_{n}(t)\right)-\frac{1}{\mu} V^{\prime}\left(t, q_{n}(t)\right) q_{n}(t)\right] d t \\
& +\sum_{j=-\infty}^{+\infty} \int_{0}^{q_{n}\left(t_{j}\right)} I(s) d s-\frac{1}{\mu} \sum_{j=-\infty}^{+\infty} I\left(q_{n}\left(t_{j}\right)\right) q_{n}\left(t_{j}\right) \\
= & \left(\frac{1}{2}-\frac{1}{\mu}\right)\left\|q_{n}\right\|_{H}^{2}-\frac{1}{\mu} \int_{\mathbb{R}}\left[\mu V\left(t, q_{n}(t)\right)-V^{\prime}\left(t, q_{n}(t)\right) q_{n}(t)\right] d t \\
& +\sum_{j=-\infty}^{+\infty} \int_{0}^{q_{n}\left(t_{j}\right)} I(s) d s-\frac{1}{\mu} \sum_{j=-\infty}^{+\infty} I\left(q_{n}\left(t_{j}\right)\right) q_{n}\left(t_{j}\right) \\
\geq & \left(\frac{1}{2}-\frac{1}{\mu}\right)\left\|q_{n}\right\|_{H}^{2}-\frac{b T p}{2}\left\|q_{n}\right\|_{H}^{2}-\frac{b T p}{\mu}\left\|q_{n}\right\|_{H}^{2} \\
= & \left(\frac{1}{2}-\frac{1}{\mu}-\frac{b T p}{2}-\frac{b T p}{\mu}\right)\left\|q_{n}\right\|_{H}^{2} .
\end{aligned}
$$

Since $b<\frac{\mu-2}{(\mu+2) T p},\left\{q_{n}\right\}$ is bounded in $H$.

Let $a_{2}:=\sup _{n \in \mathbb{N}}\left\{\left\|q_{n}\right\|_{H}\right\}$. By $\left(\mathrm{H}_{2}\right)$ and $\left(\mathrm{H}_{3}\right)$, we have

$$
\frac{1}{2} V^{\prime}(t, u) u-V(t, u)=o\left(u^{2}\right), \quad \text { as } u \rightarrow 0,
$$

which implies

$$
a_{3}:=\sup _{|u| \leq T^{\frac{1}{2}} a_{2}} \frac{\frac{1}{2} V^{\prime}(t, u) u-V(t, u)}{u^{2}}<\infty .
$$

For any $\varepsilon>0$, there exists $\delta>0$ such that, for $|u| \leq \delta$, we have

$$
\left|\frac{1}{2} V^{\prime}(t, u) u-V(t, u)\right| \leq \varepsilon u^{2}
$$

Therefore, by Lemma 2.3, we have

$$
\begin{aligned}
& \int_{\mathbb{R}} {\left[\frac{1}{2} V^{\prime}\left(t, q_{n}\right) q_{n}-V\left(t, q_{n}\right)\right] d t } \\
& \quad=\left[\int_{\left|q_{n}(t)\right|>\delta}+\int_{\left|q_{n}(t)\right| \leq \delta}\right]\left[\frac{1}{2} V^{\prime}\left(t, q_{n}\right) q_{n}-V\left(t, q_{n}\right)\right] d t
\end{aligned}
$$




$$
\begin{aligned}
& \leq \operatorname{meas}\left\{\left|q_{n}(t)\right|>\delta\right\} a_{3}\left|q_{n}\right|_{\infty}^{2}+\varepsilon\left|q_{n}\right|_{2}^{2} \\
& \leq \operatorname{meas}\left\{\left|q_{n}(t)\right|>\delta\right\} T a_{2}^{2} a_{3}+\varepsilon T^{2} a_{2}^{2} .
\end{aligned}
$$

If $q_{n}$ converges to 0 in measure on $R$, then it follows from $\left(\mathrm{H}_{5}\right)$ and $(2.10)$ that

$$
\begin{aligned}
0< & d=\varphi\left(q_{n}\right)-\frac{1}{2}\left\langle\varphi^{\prime}\left(q_{n}\right), q_{n}\right\rangle+o(1) \\
= & \int_{\mathbb{R}}\left[\frac{1}{2} V^{\prime}\left(t, q_{n}\right) q_{n}-V\left(t, q_{n}\right)\right] d t+\sum_{j=-\infty}^{+\infty} \int_{0}^{q_{n}\left(t_{j}\right)} I(s) d s-\frac{1}{2} \sum_{j=-\infty}^{+\infty} I\left(q_{n}\left(t_{j}\right)\right) q_{n}\left(t_{j}\right)+o(1) \\
\leq & \operatorname{meas}\left\{\left|q_{n}(t)\right|>\delta\right\} T a_{2}^{2} a_{3}+\varepsilon T^{2} a_{2}^{2} \\
& +\frac{1}{2} \sum_{j=-\infty}^{+\infty}\left[2 \int_{0}^{q_{n}\left(t_{j}\right)} I(s) d s-I\left(q_{n}\left(t_{j}\right)\right) q_{n}\left(t_{j}\right)\right]+o(1) \\
\leq & \operatorname{meas}\left\{\left|q_{n}(t)\right|>\delta\right\} \operatorname{Ta}_{2}^{2} a_{3}+\varepsilon T^{2} a_{2}^{2}+o(1) \\
= & o(1)
\end{aligned}
$$

a contradiction. The proof is complete.

The following lemma is similar to a weak version of Lieb's lemma [15], which will play an important role in the proof of Theorem 1.1.

Lemma 2.8 If $\left\{u_{n}\right\}$ is bounded in $H$ and $u_{n}$ does not converge to 0 in measure, then there exist a sequence $\left\{x_{n_{k}}\right\} \subset \mathbb{Z}$ and a subsequence $\left\{u_{n_{k}}\right\}$ of $\left\{u_{n}\right\}$ such that

$$
u_{n_{k}}\left(\cdot+x_{n_{k}} T\right) \rightarrow u \neq 0 \quad \text { in } H^{1}(\mathbb{R}) .
$$

Proof If

$$
\lim _{n \rightarrow \infty} \sup _{q \in \mathbb{Z}} \sup _{t \in[q T-T, q T+T]}\left|u_{n}(t)\right|=0,
$$

then, for any $\varepsilon>0$, there exists $n_{0}>0$ such that, for $n \geq n_{0}$, we have

$$
\sup _{q \in \mathbb{Z}} \sup _{t \in[q T-T, q T+T]}\left|u_{n}(t)\right| \leq \varepsilon
$$

Therefore, for all $t \in \mathbb{R}$ and $n \geq n_{0}$, we have

$$
\left|u_{n}(t)\right| \leq \varepsilon
$$

which implies

$$
\lim _{n \rightarrow \infty} \operatorname{meas}\left\{t \in \mathbb{R}:\left|u_{n}(t)\right|>\varepsilon\right\}=0,
$$

a contradiction. Therefore, there exist a constant $\rho>0$ and a subsequence $\left\{n_{k}\right\}$ of $\{n\}$ such that

$$
\sup _{x \in \mathbb{Z}} \sup _{t \in[x T-T, x T+T]}\left|u_{n_{k}}(t)\right|>\rho, \quad k \in \mathbb{N}
$$


where $\mathbb{N}$ denotes the set of all positive integers. So, for $k \in \mathbb{N}$, there exists $x_{n_{k}} \in \mathbb{Z}$ such that

$$
\sup _{t \in\left[x_{n_{k}} T-T, x_{n_{k}} T+T\right]}\left|u_{n_{k}}(t)\right|>\rho .
$$

Let $v_{n_{k}}(t)=u_{n_{k}}\left(t+x_{n_{k}} T\right), t \in \mathbb{R}$. Since $\left\{u_{n}\right\}$ is bounded in $H$, by Lemma 2.3 , it is easy to see that $\left\{v_{n_{k}}\right\}$ is bounded in $H^{1}(\mathbb{R})$. Therefore, $\left\{v_{n_{k}}\right\}$ has a subsequence which weakly converges to $u$ in $H^{1}(\mathbb{R})$. Without loss of generality, we assume that $v_{n_{k}} \rightarrow u$ in $H^{1}(\mathbb{R})$. Thus, $v_{n_{k}} \rightarrow u$ in $H^{1}([-T, T])$. Therefore, $v_{n_{k}}$ uniformly converges to $u$ in $[-T, T]$. Noticing that

$$
\sup _{t \in[-T, T]}\left|v_{n_{k}}(t)\right|=\sup _{t \in[-T, T]}\left|u_{n_{k}}\left(t+x_{n_{k}} T\right)\right|=\sup _{t \in\left[x_{n_{k}} T-T, x_{n_{k}} T+T\right]}\left|u_{n_{k}}(t)\right|>\rho,
$$

we have

$$
\sup _{t \in[-T, T]}|u(t)| \geq \rho,
$$

that is, $u \neq 0$.

Proof of Theorem 1.1 By Lemma 2.7, there exists a bounded $\left\{q_{n}\right\}$ in $H$ such that

$$
\varphi\left(q_{n}\right) \rightarrow d, \quad \varphi^{\prime}\left(q_{n}\right) \rightarrow 0, \quad \operatorname{dist}\left(q_{n}, H\right) \rightarrow 0,
$$

and $\left\{q_{n}\right\}$ does not converge to 0 in measure on $\mathbb{R}$, where $d$ is the mountain pass value. By Lemma 2.8, there exists a sequence $\left\{x_{n_{k}}\right\}$ in $\mathbb{Z}$ such that

$$
\omega_{k}:=q_{n_{k}}\left(\cdot+x_{n_{k}} T\right) \rightarrow \omega \neq 0 \quad \text { in } H^{1}(\mathbb{R}) .
$$

For any fixed $k \in \mathbb{N}$, set $s=t+x_{n_{k}} T$ and $h_{k}(s):=h\left(s-x_{n_{k}} T\right)$. Then $s_{j}:=t_{j}+x_{n_{k}} T(j \in \mathbb{Z})$ are impulsive points and

$$
\left\|h_{k}\right\|_{H}=\left(\int_{\mathbb{R}}\left|h_{k}^{\prime}(s)\right|^{2} d s\right)^{\frac{1}{2}}=\left(\int_{\mathbb{R}}\left|h^{\prime}(s)\right|^{2} d s\right)^{\frac{1}{2}}=\|h\|_{H} .
$$

For any $h \in C_{0}^{\infty}(\mathbb{R})$ with $h(k T)=0$, we have

$$
\begin{aligned}
\left\langle\varphi^{\prime}\left(\omega_{k}\right), h\right\rangle= & \int_{\mathbb{R}} \omega_{k}^{\prime}(t) h^{\prime}(t) d t-\int_{\mathbb{R}} V^{\prime}\left(t, \omega_{k}(t)\right) h(t) d t+\sum_{j=-\infty}^{+\infty} I\left(\omega_{k}\left(t_{j}\right)\right) h\left(t_{j}\right) \\
= & \int_{\mathbb{R}}\left[q_{n_{k}}^{\prime}\left(t+x_{n_{k}} T\right) h^{\prime}(t)-V^{\prime}\left(t, q_{n_{k}}\left(t+x_{n_{k}} T\right)\right) h(t)\right] d t \\
& +\sum_{j=-\infty}^{+\infty} I\left(q_{n_{k}}\left(t_{j}+x_{n_{k}} T\right)\right) h\left(t_{j}\right) \\
= & \int_{\mathbb{R}}\left[q_{n_{k}}^{\prime}(s) h^{\prime}\left(s-x_{n_{k}} T\right)-V^{\prime}\left(s-x_{n_{k}} T, q_{n_{k}}(s)\right) h\left(s-x_{n_{k}} T\right)\right] d s \\
& +\sum_{j=-\infty}^{+\infty} I\left(q_{n_{k}}\left(s_{j}\right)\right) h\left(s_{j}-x_{n_{k}} T\right)
\end{aligned}
$$




$$
\begin{aligned}
= & \int_{\mathbb{R}}\left[q_{n_{k}}^{\prime}(s) h^{\prime}\left(s-x_{n_{k}} T\right)-V^{\prime}\left(s, q_{n_{k}}(s)\right) h\left(s-x_{n_{k}} T\right)\right] d s \\
& +\sum_{j=-\infty}^{+\infty} I\left(q_{n_{k}}\left(s_{j}\right)\right) h\left(s_{j}-x_{n_{k}} T\right) \\
= & \int_{\mathbb{R}}\left[q_{n_{k}}^{\prime}(s) h_{k}^{\prime}(s)-V^{\prime}\left(s, q_{n_{k}}(s)\right) h_{k}(s)\right] d s \\
& +\sum_{j=-\infty}^{+\infty} I\left(q_{n_{k}}\left(s_{j}\right)\right) h_{k}\left(s_{j}\right) \\
= & \left\langle\varphi^{\prime}\left(q_{n_{k}}\right), h_{k}\right\rangle .
\end{aligned}
$$

Hence, we have

$$
\left|\left\langle\varphi^{\prime}\left(\omega_{k}\right), h\right\rangle\right|=\left|\left\langle\varphi^{\prime}\left(q_{n_{k}}\right), h_{k}\right\rangle\right| \leq\left\|\varphi^{\prime}\left(q_{n_{k}}\right)\right\| \cdot\left\|h_{k}\right\|_{H}=\left\|\varphi^{\prime}\left(q_{n_{k}}\right)\right\| \cdot\|h\|_{H},
$$

which implies

$$
\left\langle\varphi^{\prime}\left(\omega_{k}\right), h\right\rangle \rightarrow 0 \quad \text { as } k \rightarrow \infty .
$$

Since $H \subset H^{1}(\mathbb{R}), \omega_{k} \rightarrow \omega$ in $H$, therefore

$$
\int_{\mathbb{R}} \omega_{k}^{\prime} h^{\prime} \rightarrow \int_{\mathbb{R}} \omega^{\prime} h^{\prime}
$$

As $\omega_{k} \rightarrow \omega$ in $H^{1}(\mathbb{R}),\left\{\omega_{k}\right\}$ is bounded in $H^{1}(\mathbb{R})$ and hence $\left|\omega_{k}\right|_{\infty} \leq c$ for some $c>0$ and all $k \in \mathbb{N}$. Also, $\left\{\omega_{k}\right\}$ uniformly converges to $\omega$ on $\operatorname{supp}(h)$ and, $V^{\prime}$ being uniformly continuous on $\operatorname{supp}(h) \times[-c, c], V^{\prime}\left(t, \omega_{k}\right) h$ uniformly converges to $V^{\prime}(t, \omega) h$ on $\operatorname{supp}(h) \times[-c, c]$. By the Lebesgue dominated convergence theorem, this implies that

$$
\int_{\mathbb{R}} V^{\prime}\left(t, \omega_{k}\right) h \rightarrow \int_{\mathbb{R}} V^{\prime}(t, \omega) h
$$

For any $h \in H$ and $\varepsilon>0$, take $J_{0}$ sufficiently large such that

$$
\left(\sum_{j=J_{0}+1}^{+\infty}\left|h\left(t_{j}\right)\right|^{2}\right)^{\frac{1}{2}} \leq \varepsilon, \quad\left(\sum_{j=-\infty}^{-J_{0}-1}\left|h\left(t_{j}\right)\right|^{2}\right)^{\frac{1}{2}} \leq \varepsilon .
$$

Since $\omega_{k} \rightarrow \omega$ in $H^{1}(\mathbb{R}), \omega_{k} \rightarrow \omega$ in $H^{1}\left(\left[t_{-J_{0}}, t_{J_{0}}\right]\right)$, therefore $\omega_{k}$ uniformly converges to $\omega$ in $\left[t_{-J_{0}}, t_{J_{0}}\right]$. By the continuity of $I$, there exists $K>0$ such that, when $k>K$, we have

$$
\left|\sum_{j=-J_{0}}^{J_{0}}\left[I\left(\omega_{k}\left(t_{j}\right)\right)-I\left(\omega\left(t_{j}\right)\right)\right] h\left(t_{j}\right)\right| \leq \varepsilon .
$$

Since

$$
\left|I\left(\omega_{k}\left(t_{j}\right)\right)\right| \leq b\left|\omega_{k}\left(t_{j}\right)\right|, \quad\left|I\left(\omega\left(t_{j}\right)\right)\right| \leq b\left|\omega\left(t_{j}\right)\right|
$$


it follows from Lemma 2.3 that

$$
\begin{aligned}
& \left(\sum_{j=J_{0}+1}^{+\infty}\left[I\left(\omega_{k}\left(t_{j}\right)\right)-I\left(\omega\left(t_{j}\right)\right)\right]^{2}\right)^{\frac{1}{2}} \\
& \quad \leq \sqrt{2} b\left(\sum_{j=J_{0}+1}^{+\infty}\left[\left|\omega_{k}\left(t_{j}\right)\right|^{2}+\left|\omega\left(t_{j}\right)\right|^{2}\right]\right)^{\frac{1}{2}} \\
& \leq \sqrt{2} b\left[\operatorname{Tp}\left(\left\|\omega_{k}\right\|_{H}^{2}+\|\omega\|_{H}^{2}\right)\right]^{\frac{1}{2}} \\
& \leq 2 b \sqrt{T p} \max \left\{\sup _{k}\left\|\omega_{k}\right\|_{H},\|\omega\|_{H}\right\} .
\end{aligned}
$$

Similarly, we have

$$
\left(\sum_{j=-\infty}^{-J_{0}-1}\left[I\left(\omega_{k}\left(t_{j}\right)\right)-I\left(\omega\left(t_{j}\right)\right)\right]^{2}\right)^{\frac{1}{2}} \leq 2 b \sqrt{T p} \max \left\{\sup _{k}\left\|\omega_{k}\right\|_{H},\|\omega\|_{H}\right\} .
$$

By the Cauchy-Schwarz inequality, we have

$$
\begin{aligned}
\mid \sum_{j=-\infty}^{+\infty} & {\left[I\left(\omega_{k}\left(t_{j}\right)\right)-I\left(\omega\left(t_{j}\right)\right)\right] h\left(t_{j}\right) \mid } \\
\leq & \left|\sum_{j=J_{0}+1}^{+\infty}\left[I\left(\omega_{k}\left(t_{j}\right)\right)-I\left(\omega\left(t_{j}\right)\right)\right] h\left(t_{j}\right)\right|+\left|\sum_{j=-J_{0}}^{J_{0}}\left[I\left(\omega_{k}\left(t_{j}\right)\right)-I\left(\omega\left(t_{j}\right)\right)\right] h\left(t_{j}\right)\right| \\
& +\left|\sum_{j=-\infty}^{-J_{0}-1}\left[I\left(\omega_{k}\left(t_{j}\right)\right)-I\left(\omega\left(t_{j}\right)\right)\right] h\left(t_{j}\right)\right| \\
\leq & \left(\sum_{j=J_{0}+1}^{+\infty}\left|I\left(\omega_{k}\left(t_{j}\right)\right)-I\left(\omega\left(t_{j}\right)\right)\right|^{2}\right)^{\frac{1}{2}}\left(\sum_{j=J_{0}+1}^{+\infty}\left|h\left(t_{j}\right)\right|^{2}\right)^{\frac{1}{2}}+\left|\sum_{j=-J_{0}}^{J_{0}}\left[I\left(\omega_{k}\left(t_{j}\right)\right)-I\left(\omega\left(t_{j}\right)\right)\right] h\left(t_{j}\right)\right| \\
& +\left(\sum_{j=-\infty}^{-J_{0}-1}\left|I\left(\omega_{k}\left(t_{j}\right)\right)-I\left(\omega\left(t_{j}\right)\right)\right|^{2}\right)^{\frac{1}{2}}\left(\sum_{j=-\infty}^{-J_{0}-1}\left|h\left(t_{j}\right)\right|^{2}\right)^{\frac{1}{2}} \\
\leq & {\left[1+4 b \sqrt{T p} \max \left\{\sup _{k}\left\|\omega_{k}\right\|_{H},\|\omega\|_{H}\right\}\right] \varepsilon, \quad \forall k>K . }
\end{aligned}
$$

Therefore,

$$
\lim _{k \rightarrow \infty} \sum_{j=-\infty}^{+\infty} I\left(\omega_{k}\left(t_{j}\right)\right) h\left(t_{j}\right)=\sum_{j=-\infty}^{+\infty} I\left(\omega\left(t_{j}\right)\right) h\left(t_{j}\right) .
$$

From (2.11)-(2.14), we have

$$
\left\langle\varphi^{\prime}(\omega), h\right\rangle=\lim _{k \rightarrow \infty}\left\langle\varphi^{\prime}\left(\omega_{k}\right), h\right\rangle=0
$$

Thus, $\varphi^{\prime}(\omega)=0$ and $\omega$ is a nontrivial weak homoclinic orbit of (1.1)-(1.2). 


\section{Competing interests}

The authors declare that they have no competing interests.

\section{Authors' contributions}

All authors contributed equally to the manuscript and read and approved the final manuscript.

\section{Acknowledgements}

This research is supported by the National Natural Science Foundation of China (Grant No. 10971085). The authors would like to thank the anonymous reviewers for their valuable comments and suggestions to improve the manuscript.

\section{Received: 25 July 2012 Accepted: 7 November 2012 Published: 26 November 2012}

\section{References}

1. Fečkan, M: Chaos in singularly perturbed impulsive O.D.E. Boll. Unione Mat. Ital, B 10, 175-198 (1996)

2. Battelli, F, Fečkan, M: Chaos in singular impulsive O.D.E. Nonlinear Anal. 28, 655-671 (1997)

3. Tang, $\mathrm{XH}, \mathrm{XiaO}, \mathrm{L}$ : Homoclinic solutions for nonautonomous second order Hamiltonian systems with a coercive potential. J. Math. Anal. Appl. 351, 586-594 (2009)

4. Tang, XH, Xiao, L: Homoclinic solutions for a class of second-order Hamiltonian systems. Nonlinear Anal. 71 1140-1152 (2009)

5. Tang, $\mathrm{XH}$, Lin, XY: Homoclinic solutions for a class of second-order Hamiltonian systems. J. Math. Anal. Appl. 354, 539-549 (2009)

6. Tang, $\mathrm{XH}$, Lin, $\mathrm{XY}$ : Existence of infinitely many homoclinic orbits in Hamiltonian systems. Proc. R. Soc. Edinb. A 141, 1103-1119 (2011)

7. Nieto, J, O’Regan, D: Variational approach to impulsive differential equations. Nonlinear Anal., Real World Appl. 10 680-690 (2009)

8. Zhang, H, Li, ZX: Periodic and homoclinic solutions generated by impulses. Nonlinear Anal., Real World Appl. 1, 39-51 (2011)

9. Han, X, Zhang, H: Periodic and homoclinic solutions generated by impulses for asymptotically linear and sublinear Hamiltonian system. J. Comput. Appl. Math. 235, 1531-1541 (2011)

10. Chen, H, Sun, J: An application of variational method to second-order impulsive differential equation on the half-line. Appl. Math. Comput. 217, 1863-1869 (2010)

11. Sun, J, Chen, $\mathrm{H}$, Yang, L: The existence and multiplicity of solutions for an impulsive differential equation with two parameters via a variational method. Nonlinear Anal. 73, 440-449 (2010)

12. Luo, Z, Xiao, J, Xu, J: Subharmonic solutions with prescribed minimal period for some second-order impulsive differential equations. Nonlinear Anal. 75, 2249-2255 (2012)

13. Smets, D, Willem, M: Solitary waves with prescribed speed on infinite lattices. J. Funct. Anal. 149, 266-275 (1997)

14. Brezis, H, Nirenberg, L: Remarks on finding critical points. Commun. Pure Appl. Math. 64, 939-963 (1991)

15. Lieb, EH: On the lowest eigenvalue of the Laplacian for the intersection of two domains. Invent. Math. 74, 441-448 (1983)

doi:10.1186/1687-2770-2012-138

Cite this article as: Fang and Duan: Existence of nontrivial weak homoclinic orbits for second-order impulsive differential equations. Boundary Value Problems 2012 2012:138.

\section{Submit your manuscript to a SpringerOpen ${ }^{\ominus}$ journal and benefit from:}

- Convenient online submission

- Rigorous peer review

- Immediate publication on acceptance

- Open access: articles freely available online

High visibility within the field

- Retaining the copyright to your article 